\title{
Psiko-sosyal Açıdan \\ Küreselleşme, Empoze Kültür ve Davranışa Yansıması
}

\author{
Dr. Osman SEZGIN* \\ Marmara Üniversitesi, Atatürk Eğitim Fakültesi, Göztepe Kampüsü, 34722 Kadıköy / İstanbul / Türkiye
}

\author{
Psk. A. Sena SEZGIN
}

Kalem Eğitim Kurumları, Turistik Çamlıca Cad. No:68 Büyük Çamlıca / Üsküdar / İstanbul / Türkiye

\begin{abstract}
Özet
Globalleşme/küreselleşme, tamamen olumsuz olmamakla birlikte tamamen de olumlu değer realitelerini içermez. Günümüzde o her değeri etkilediği gibi Türk kültürünü de etkilemekte ve kahir ekseriyeti oluşturan olumsuz yönleriyle tehdit etmektedir. Kaçınılmaz ve karşı konulamaz bir olgu olan küreselleşme karşısında millî kültürün korunması, milletin bekası için zorunlu görünmektedir.

Bununla birlikte tarihî olarak, Türk kültürünü belirleyen değer, sosyal unsurlar ve formlar değişikliğe uğramıştır. Nitekim kültür, statik değildir. Temel değerler aynı kalmak şartıyla değişen ve gelişen ilişkiler ağıdır. Kültür her toplumsal olgu ve değer gibi dinamik karakterle değişerek yenilenir. Türk kültürünün öz nitelikleri arasında değişkenlik ön plandadır. Böyle bir yapıya sahip olan Türk kültürü, karşı konulamaz bir güç görünümünde olan küreselleşme karşısında, varlık ve etkinliğini

* Sorumlu Yazar. Tel:+90 2165219797 E-posta: osezgin@marmara.edu.tr

(C) 2011 Kalem Eğitim ve Sağlık Hizmetleri A.Ş. Bütün Hakları Saklıdır ISSN: 2146 - 5606
\end{abstract}


nasıl korumalıdır? Bu makalede bu soruya cevap aranmaktadır.

Anahtar Kelimeler: Millî kültür; Değişim; Kültür değişmesi; Kimlik; Küreselleşme.

\title{
Globalization by Psycho-social Point of View, Imposed Culture and Its Reflections in Behaviour
}

\begin{abstract}
Globalization has not absolutly containes negative values as such in positive. Globalization has been the more contentious, because it has effects both good and bad, there is another domain of globalization, that of culture and identity.

Globalization has increased contacts between people and their values, ideas and ways of life in unprecedented ways.

The main purpose of this study is to focus on the concept of Turkish culture whose essential nature and functions are forced to change with the influence of globalization. The effects of globalization on the Turkish culture will be discussed in the framework of national culture.

Key Words: National culture; Change; Cultural change; Identity; Globalization.
\end{abstract}

\section{Kelimeden Kavrama Kültüre Kısa Bir Bakış}

Her kelime, kavram ve kuram bir yönü ile kullanan ve icat eden şahsın hayatını yansıtırken öbür yanı ile de ait olduğu kültürün ve felsefi görüşün düşüncelerini de içinde taşır. Dolayısı ile bir kelime, kavram ve kuram bir kültürden başka bir kültüre nakledilirken veya çevirisi yapılırken doğru bir tercümenin veya naklin yapılabilmesi, yanlışa veya hataya düşülmemesi için mutlaka söz konusu kelime kavram ve kuramı icat edip kullanan kimsenin fikrî yapısını, hayat öz geçmişini ve ait olduğu kültürü ve o kültürü oluşturan felsefi akımı dikkate almak vazgeçilemez bir zorunluluk olarak karşımıza çıkmaktadır. 
Bir başka ifade ile bir kelimeden farklı anlamlar anlayan ile bir manayı başka kelimelerle ifade edenlerin anlaşmaları mümkün değildir.

Makalemizin konusunu teşkil eden küreselleşme ve kültür kelimeleri de bu çerçevede değerlendirilmelidir diye düşünmekteyiz.

Kültür kelimesi dilimize Fransızcadan girmiştir. Kelimenin kökü toprağ1 ekip biçmek anlamında Latince "colore" mastarından türemiştir. Günümüzde kültür kelimesinin yüz altmıştan fazla anlamı vardır. Bu durum söz konusu kelimeyi belirsiz yapmaktadır diyebiliriz (Meriç, 1986).

Cumhuriyetin ilk yıllarında yapılan devrimler açısından pratikte âcil çözümlerin gerekli olduğu zamanlarda E. Durkheim sosyolojisi ile tanışan Ziya Gökalp kültürümüzü muhafaza edip Batı'nın ilim ve tekniğini alalım, yani Batı medeniyetine girelim fikrini ifade ederken bahis mevzusu kelimeyi Türkçeye "hars" olarak çevirmiştir (Güngör, 2006). Bu kelime de köken itibari ile Arapçadır (Meriç, 1986). Söylenişinin latif olmamasının yanı sıra anlamlarının da zarif olduğunu söylemek bir hayli zor görünmektedir. Bu durumda bir müddet "hars" kelimesi kullanılmış ve bilahare öz Türkçecilik akımının tesiri ile kültür kelimesinin Türkçe karşılığ1 olarak “ekin” kelimesi teklif edilmiştir.

Aslında telaffuzu ve anlamı itibari ile irfan kelimesi kültür kelimesinin kastedilen anlamlarını kapsadığı gibi söylenişindeki letafet de ayrıca zikredilmeye değer diye düşünmekteyiz. Bilmek, özüne vâkıf olmak, künhüne ermek; neden ve niçinlerini en soyut anlamda ve idealistçe tespit etmek gibi fevkalade kapsamlı anlamları olan irfan kelimesi hâlâ kültür kelimesinin Türkçe karşılığı olarak kullanılabilecek en mutena ve müstesna bir kelimedir denilebilir.

İrfan kelimesi anlamları itibari ile birleştirici iken kültür kelimesi aslî görevi itibari ile ayrıştırıcıdır denilebilir.

Batı'nın ve küreselleşmenin her alanda olduğu gibi akademik hayat- 
taki etkinliği veya kültürel açıdan empoze tavrı yüzünden Türkçe bütün anlamları terk edilip artık kültür kelimesi kullanılmaya başlanmıştır.

Küreselleşme kavramının Batı dillerindeki karşılığı ise globalizmdir. Top gibi yuvarlak, dairevi anlamlarına gelen bu kelimenin kökü ise “glob”tur (Webster, 1988).

Küreselleşme kelimesinin kökü ise küre kelimesidir. Küre gibi olan, bütün dünyaya ait anlamlarındaki bu kelime günümüzde yaygın bir kullanım alanı bulmuştur.

Küreselleşme kelimesinden başka bu alanda bölgeselleşme kelimesi de çok önemli bir kavram olarak karşımıza çıkmaktadır. Küreselleşmenin tesirlerine kar da diyebileceğimiz bir gayretin sonucu çeşitli faktörlerle bir araya gelen grupların oluşturduğu yapıya glokalleşme ismi verilmiştir. Bu kelime global kelimesinin glob kısmı ile lokalleşme kelimesinin birleşmesinden meydana gelmiştir (Petras, 2002).

Globalleşme ve glokalleşmenin yanı sıra lokalleşme kavramı da bu konu irdelenirken iyi bilinmesi gereken bir kavramdır denilebilir. Birbiri ile barışmış, bağdaşmış, kaynaşmış, anlaşmış ve müşterek yaşamayı başarmış etnik ve dinsel azınlıkların ön yüzü ile kendilerini dünyaya duyurmak, anlatmak için iletişim ve ulaşım vasıtalarının etkin kullanımı ile geri planda beraber oldukları topluluklardan ayrılmayı ve ayrıştırılmayı oluşturan bir gayretin ifadesidir denilebilir.

Yeri ve zamanı geldikçe kelimelerin köken ve anlamlarına tekrar dönülecektir. Ancak gerek akademik ve gerekse günlük kullanım açısından Türkçenin ciddi derecede kısırlaştığı, geçmişle bağının iyice koptuğu ve Batılı bilimlerin kavramlarının hâkim olduğu bir dönemde girişte bir nebze de olsa kelimelerin köken ve anlamlarından bahsetmenin söz konusu hatalardan uzak kalabilme adına bir gayret olmasının anlayışla karşılanmasını ümit etmekteyiz. 


\section{Giriş}

İnsanların toplum hâlinde yaşadıkları, yani bir kültür oluşturdukları her yer ve zamanda kişi olarak da, toplum olarak da bir kimlikleri oluşmuştur. İnsanların ben ve başkalarının farkına varmakla başlayan kişilik oluşumu gibi, toplumun kimliğinin farkına varması da, doğrudan bir kavga sebebi değildir. Kültürün mecrası, sosyal kimliğin oluşum sürecidir. Ancak kültürün kendi imanından aldığı ölçülerle hayatın maddesinin biçimlendirdiği, hayatın her alanında çözümler üretip kurumlaştı̆̆ 1 olgunluk döneminden itibaren, kimlikte de sıkıntılar başlar (Köseoğlu, 1996, s.86).

Bu nedenle ülkemizde tartışılabilecek olan kimlik sorunları, hızlı değişmelerden doğan sıkıntılardır. Hızlı diye nitelendirdiğimiz değişmeleri de, birkaç grupta düşünebiliriz. Önce Osmanlı döneminden başlayan ve Batılılaşma yahut asrileşme olarak isimlendirilen gelişmelere işaret etmeliyiz. Bu değişmeler Tanzimat'tan itibaren, aynı zamanda resmî kanallardan kültürümüze aşılanmaya çalışılmıştır. Aynı yöndeki değişmeler, yakın döneminde hukuki yaptırımlar altında kültürümüze mal edilmeye çalışılmış, millî kültürün iman alanına kadar girilmiş, değiş̧me için zorlanmalar yapılmıştır (Köseoğlu, 1996, s.88).

Kültür zorla oluşturulamaz. Zira kültür, bir toplumun tarih içinde oluşturduğu değer, norm ve sosyal kontrol sistemlerinin göstergesi olan maddi ve manevi unsurlarla bunların şekillendirdiği ilişkiler ağında, sınır koyma, aklileştirme ve model olanı göstermek suretiyle kimlik kazandırır, mensubiyet şuuruna sebep olur. Bu kimlik kazandırır, mensubiyet şuuru uyandırış bir insanı, bir taraftan geçmişteki insanlara, bir taraftan günümüze beraber yaşadığ yahut çeşitli sebeplerle ayrı kaldığı insanlara, bir taraftan da gelecek nesillere bağlayan fonksizyonalizasyon, rasyonalizasyon ve modelizasyon türünden kurallar ve uygulamalarla gerçekleşir (Tural, 1992, s.122). Kültürün bu yapısal özelliği itibarıyla bir 
anlamda Türk kültürü bu tür bir rasyonalleşme ile uyum arzetmektedir (Özakpınar, 2007, s.550).

Uzun bir sürece dayanan kültür aynı zamanda sürekli değișebilir. Bilginin gelişme ve yayılma hızı, değişimin süratini belirleyen etkenlerdendir. Tarihin hiçbir döneminde bugünkü kadar bilginin hızlı gelişip yayıldığı görülmemiştir. Bunu daha iyi anlamak için, tıptan iktisada, sosyal hayattan siyasete ve hatta uluslararası ilişkilere kadar ulaşan klasik şartlanmadan etkili (edimsel) koşullanmaya ve ondan da bilişselciliğe geçişin değişim ve yayılma hızına bakmak yeterli olacaktır. Geçmişte, dünyanın herhangi bir yerinde bir bilimsel buluşun ortaya çıkması, yayılması ve bireysel ve toplumsal hayati etkileyerek değişime sebep olması, bir hayli zaman aldığı bilinen bir husustur. Günümüzde ise bilginin yayılma hızının, bir tuşa dokunma süresine indiği görülmektedir.

Olumlu ve olumsuz yönde olmak üzere değişimin iki boyutu vardır. Olumsuz olanına gerileme denilirken; olumlu yönde olanına ise gelişme denilir.

Değişim, maddi-manevi, psikolojik, sosyolojik, fizyolojik, entelektüel, duyuşsal-bilişsel (duygusal, hissî) iradî, mental gibi her alanda, her noktada olabilir. Değişim önce zihinde başlar, kelimelerle ve uygulamalar ile maddi hayatta yerini alır. Zihindeki değişim düşünce yapısını doğrudan etkilemektedir.

Değişim, psiko-sosyal nitelikli olduğu için, sebebi tek bir nedene indirgenemez. Dolayısı ile günümüz dünyasındaki değişim, bir yönü ile bilimdeki gelişme ve yayılma hızı ile ilgili iken; öbür taraftan bilimin kaynağı ile ilgili tartışmalardan neşet eden ideolojilerin yanında başka etkenlerin de tesiri altında olduğu gözden rak tutulamaz. Bütün bunların temelinde ise, insanoğlunun sınırsız arzu ve isteklerini tatmin için sınırlı güç-kuvvet ve imkânlarını zorlaması olduğunu da belirtmeliyiz. 
Değişimin sosyo politik ve kültürel boyutu, bazı olumlu gelişmelere katkı sağladığ 1 gibi, bazen de toplumsal sorunlara yol açabilmektedir. Nitekim bir taraftan, "tüketim” anlayışına dayanan gelişmiş Batı toplumlarının zihniyeti; diğer yandan egemen unsur hâline gelen bilgi ve bilginin pratiğe aktarılması demek olan teknolojinin insan emeğine ihtiyacı azaltmak suretiyle istihdam yapısındaki değişimin sonucu, artan işsiz insan sayısı, büyük çaplı bunalımların ortaya çıkmasına neden olmaktadır (Bussolo ve Jeffery, 2006, s.51).

Bahis mevzusu değişim, bir yönü ile günümüzde var olan bütün millet ve devletleri etkilerken, öte yandan bu etkileşimin boyutları sosyal, siyasal, iktisadi, kültürel ve eğitimsel yönleri ile etkisini her geçen gün artırmaktadır. Globalleşmenin tesirinin bütün ülke ve devletleri kapsayacak nitelikte olması nedeniyle, yapılacak analiz, sentez, çözüm, çare ve anlamalar/anlamlandırmaların da o boyutta olması gerekmektedir (Wright, 2000, s.56).

Globalleşme/küreselleşmenin oluşturduğu değişimin olumlu olduğu gibi olumsuz boyutları bulunmaktadır. Zira çok yönlü ve çok etmenli olan sosyal ve psiko-sosyal hiçbir olay ve olgu tamamen iyi veya bütünü ile kötüdür gibi bir anlayışla izah edilemez.

\section{Küreselleşme (Globalleşme)}

Yeni bir kavramın icat edilip kullanılmaya başlamasından maksat, bir değişimin ve bu değişime ait sürecin operasyonel bir tarzda ifadelendirilerek, yanlış anlaşılmaları bertaraf etmektir.

Kavramların ilk kullanılmaya başlandığı zamanki mana yükü ile sonraki dönemlerde verilen anlam yükünün farklarının olacağı aşikârdır.

Kökü Latince globus kelimesine dayanan globe, "bütün dünyay1 kapsayan" anlamında olan globalizm kelimesinin kökünün küre biçiminde herhangi bir cisim, içi boş top, dünya, küreye benzeyen herhangi bir 
cisim, yuvarlak bir kap gibi anlamlara gelir. Bu kelimenin damla, topak anlamına gelen glob biçimi de sözlüklerde yer almaktadır.

Sifat olarak "globular" ve "globose" ise evrensel, küre şeklinde, küresel, yuvarlaklardan meydana gelen demektir.

İsim olarak "globalism" ise, kitle iletişim araçlarının ve hızlı ulaşım vasıtalarının bir sonucu olarak bütün dünyanın tek bir yapıda olması gibi olması ve/veya algılanması manasına geldiği belirtilmektedir.

Bir başka tarife göre ise global "bütünü ile ele alınmış olan” anlamındadır. Batı dillerinde global kelimesine yüklenen mana da buna yakındır. Mesela tümdengelim metodunun Fransızcadaki karşılığı olan "Methode globale" ifadesi bunun bir göstergesidir.

Kavram olarak globalleşmenin çeşitli tarifleri bulunmaktadır. Bunun birden fazla tanımının bulunmasının sebebi ise, tarifi yapanların fikrî yapılarından, hayat telakkilerinden veya tanımı yaparken bu süreci oluşturan unsurlardan birine diğerlerine daha fazla ehemmiyet atfetmelerinden veya öne çıkarmalarından kaynaklanmaktadır diyebiliriz (Petras, 2002, s.73).

Nitekim dünyanın birçok yerinde arabalar, hava alanları, binalar, kılık-kıyafet, ayakta hızlı yemek yeme (fast food) gibi hususlardaki benzerliklerin görülmesi, küreselleşmenin bir boyutu olan kültürel globalleşmenin etkinliğinin sonucudur (Bostanc1, 1990, s.32).

Globalleşme teriminin kullanılmaya başlanılması zamanına ait değişik görüşler ileri sürülmektedir. Kimisi ilk olarak kelimeyi 1963’te Kanadalı Sosyolog Marshall Mc Luhan'ın “global köy” (global village) ifadesi ile gündeme getirdiğini söylerken, kimileri de 1980'lerde Harvard, Columbia gibi Amerikan okullarında kullanmaya başlanıldığını ve popülerleştiğini ifade etmektedirler (Marshall ve Powers, 1992, s.95).

Küreselleşme siyasi, sosyal, iktisadi ve kültürel değerlerin ve bu 
değerler etrafında toplanmış kazanımların milli sınırlar dışına taşarak dünyaya yayılmasıdır. Buna göre küreselleşme farklı kültürlerin daha yakından tanınmasını sonuç veren bir süreçtir.

Bir başka ifade ile maddi ve manevi hayatın ülke sınırları dışına taşarak başkalarını etkilemesi veya etkilenmesi söz konusudur denilebilir (Güngör, 1980, s.23).

Burada sorulması gereken soru, hangi kültürün etkin olduğudur. Yoksa kültürler birbirlerini eşit seviyede mi etkileyeceklerdir? Güçlü, baskın veya hâkim kültürden söz edilebilecek mi? Güçlü olanlar gerçekten adil davranarak güçsüz olanların kendilerini anlatmasına imkân tanıyacaklar mı? Örneğin bir parfüm reklamı yapılırken veya bir ürün tanıtılırken neden meşhur, tanınmış bir kimsenin varlı̆̆ından istifade ediliyor? Reklamı iyi yapabilmek için para ve teknolojiye sahip olan ile bunlardan mahrum olanlar aynı derecede etkili olabilir mi? (Kızılçelik, 2004, s.18)

Kısaca sosyal, siyasi, iktisadi ve kültürel açıdan milli sınırlar ötesine taşarken güç, imkân ve genelde her türlü şartlar açısından kim kime ne ölçüde şahsiyetinden taviz vermeden yakınlaşarak kutuplaşmalar ortadan kalkacak? (Kızılçelik, 2004, s.19)

Küreselleşmenin, soğuk savaş döneminden sonra, Batı'nın zaferini yeni bir yöntemle dünya geneline yayması olduğu ileri sürülmüştür. Uluslararası sermaye bu durumda hâkimiyetini kayıtsız şartsız hâle getirmekte ve dünya genelinde tekelleşmektedir (Tomlinson, 2004, s.37).

Buna göre, küreselleşmeyi emperyalizmin yeni yüzü olarak tanımlamak mümkündür (Boratav, 2004, s.25). "Emperyalizmin yeni yüzü küreselleşmedir" diyenler fikirlerini ispatlamak için şu düşünceleri öne sürmektedirler:

Küreselleşme sonucu ortaya çıkan olumsuzluklar, globalleşmenin 
menfî yönünün uzantıları olarak kabul edilmektedir. Nitekim 1900'lü yıllarda, Güney ve Güney Doğu Asya ülkeleri ile Afrika ülkeleri, Bat1lılar tarafından birer sömürge hâline getirilmişti. Günümüzde Hindistan, Pakistan ve Bangladeş İngilizlerin; Endonezya, Hollanda'nın; Filipinler ABD'nin sömürgesi idi. Afrika'nın ise nerede ise tamamı Batılı devletlerin sömürgesi altındaydı. Daha önce İspanyol ve Portekiz sömürgesi olan Latin Amerika ülkeleri ise 1820'lerde siyasi bağımsızlıklarını ancak kazanabilmişlerdi (Kloby, 2005, s.439).

Dünyada hâkimiyetini sürdüren tek ekonomik sistemin her şeyin ölçüsü olarak iktisadi başarıyı ve maddi tatmini kabul eden kapitalizm olduğu söylenebilir. Kapitalizmin, hedeflediği maddi gelişim önemli bir yol almışsa da, insanları mutlu edip etmediği şüphelidir. Zira bu başarı, istenilen ölçüde kitlelere yayılamadığı gibi, çoğu zaman servet sahibi fertler bile yalnızlığa itilmekten kurtulamamıştır. İster birey, ister toplum bazında olsun tatmin değil doyumsuzluk hâkimdir (Wood, 1999, s.72). Diğer yandan Batı medeniyeti insanı yalnızlaştırılmış toplumların arenası hâline ve insanın sosyalleşmesi bakımından çöküntünün eşiğine getirmiştir. Erich Fromm'un konuyla ilgili tespitleri dikkat çekicidir. Kapitalist bir taban üzerine oturmuş olan Batı medeniyeti, O. Spengler'in Batı'nın Çöküşü, Toynbee'nin Medeniyet Yargılanıyor ile Tarih Bilinci adlı çalışmalarında ciddi anlamda eleştiriye tabi tutulmuştur.

1997 yılı Temmuz ayında Malezya'da bir araya gelen Asyalı ilim ve fikir insanları küreselleşmeyi iktisadi, teknik, kültürel ve dinî boyuttan ele aldılar. Konferansın konusu, büyük medeniyet ve dinlerin beşiği olan Asya'da kendi kimliğini koruyarak yaşamak ile küreselleşme sürecinin kesişme alanı idi. Müzakereciler yapmış oldukları fikir alışverişlerinde daha çok küreselleşmenin insanlığa açtığı sorunlar üzerinde fikir yürüttüler.

Uluslararası dev şirketlerin ve güdümündeki yerli ortakların tek 
amacı kârı artırmak olunca, tabiat ana ihmal edilmekte, çevre kirliliği dünyanın pek çok yerinde tehlike çanlarının çalınmasını gerektirecek kadar artmaktadır. Fakirlik globalleşme ile bir ölçüde azalsa da, dünyanın farklı bölgelerinde ve hatta aynı ülkenin içinde küreselleşmeden doğan kârlar, büyük uçurumlar yaratmıştır. Sanayici ve tüccar olan kesimle, tarım kesimi arasında uçurumlar doğmuştur. Güneydeki birçok ülke, yabancı sermayenin yatırımını kolaylaştırmış, ama halkın en temel ihtiyaçlarının karşılanması kâr ve pazar adına geriye itilmiştir.

Global sermayenin borsa dalgalanmalarının uçucu ve kaçıcı olması, bir anda birçok insanın işsiz ve aç kalmasına yol açabilmektedir. Küreselleşen iktisadi hayatın bir tür kumara dönüşmesi israfa varan bir tüketim kültürünün yaygınlaşması, en azında telkin edilebilmesi ve global medya ile lokal kimliklerinin tarihten silinerek, giyimden mimariye kadar bütün dünyada monoton bir hayat tarzının hükümferma olmasına gayret edilmesi insanlık haysiyetine aylandır (Meriç, 2002, s.18).

Küreselleşme istikametindeki mevcut bütünleşme oluşumları (AB, ASEAN, NAF-TA, APEC) iyi gözlendiğinde, dünyanın herkesin huzur ve barış içinde dâhil olabileceği bir küreselleşmeye doğru mu yoksa birçok ülkenin katılabileceği bir zenginler kulübü oluşturarak kısmi bir küreselleşmeye doğru mu gittiği sorusuna cevap bulmak zorunda kal1nacaktır. Bu dengesizlikler içinde kurulan yeni bir dünya düzeni midir yoksa düzensizliği mi?

Bu bağlamda küreselleşme ile iktisadi, siyasi, sosyal ve kültürel değerler ve bu kültür değerleri çerçevesinde oluşmuş birikimler, millî sınırlar dışına taşarak dünya geneline yayılmış durumdadır. Farklı kültürlerin ve inançlarının daha yakından tanınması; ülkeler arası her türlü ilişkinin yaygınlaşması ve yoğunlaşması; ideolojik ayrımlara dayalı kutuplarının ortadan kalkması hedeflenen bir süreç olarak kabul edilmektedir. Ancak realite bağlamında Batı'nın zaferini ve hâkimiyetini yeni 
bir açılımla dünya geneline yayması; bu egemenliği perçinlemek üzere, siyasetin yanında bilim ve teknolojiyi de kullanarak bütün toplundan kendi modeline göre "modernleştirme" adı altında, değiştirmeye çalıştı̆̆ 1 görünümündedir. Olumlu gibi gözüken ilk durumda da, nihai tahlilde millî kültürler açıdan mutlaka ve sürekli bir olumsuzluk gözükmüyor mu? Toplumlar statik kalamaz, kalmamalıdır da. Fakat ne için, nereye doğru ve kimin çıkarma göre değișeceklerdir sorusu üzerinde durulmalıdır (Güngör, 1995, s.149).

Bu tür bloklaşmaların dünya üzerinde kurduğu kültür hâkimiyetinin millî kültürleri farklı boyutlarda şekillendirdiği hâlde, bunlar karşısında millî kültürlerin dinî ve ananevi değerlere dayanarak dinamizmlerini artırıp canlandıkları, hatta marjinal etnik kültürlerin bile dirilme istidadı gösterdikleri gözlenebiliyor. Bunlar bloklaşmalara ve küreselleşmeye karşı yerelleşme diye adlandırabileceğimiz kendiliğinden ortaya çıkan bir hareket midir, yoksa dünyayı kendi hâkimiyetleri altına almak gayesi ile küreselleştirme niyetinde olanların bir savaş taktiği mi? Millî değerler tahrip edilerek mahallî ayrıntılara mı dönüştürülmek isteniyor? Bütünleşme yoluna ayrışma tohumları mı ekiliyor? Küreselleşmecilerin millî birlik ve devletin aşıldığı tezi gerçekten doğru mu? Yoksa küreselleşmecilik, bir zamanların kolonicilik, sömürgecilik gibi terimlerle ifade edilen yayılmacılığın devamı mıdır? İmparatorluklardan sonra şimdi de yıkılma sırası millî kültürlerde, millî devletlerde mi?

Bu sorulara cevap verebilmek için küreselleşmenin ana boyutlarını tespit etmemiz gerekmektedir. Küreselleşme iki boyutlu kabul edilmektedir. Bunlardan birisi maddelerin yaygınlaşmasıdır. Diğeri ise, değerlerin yaygınlaşmasıdır. Bu değerler daha çok hâkim ekonomi ve kültürün maddeci, faydacı, ferdi tekelleştirici değer hükümleridir. Bunun yanında demokrasi ve demokratik değerler, insan hakları, çevre şuuru, bilginin yaygınlaşması, teknolojik gelişme, mal ve hizmet kalitesinde standart- 
laşma gibi olumlu değerler de yaygınlaşmaktadır. Küreselleşme ile bazı konular evrensel standartlara kavuşmakta, evrensel düşünülmektedir.

Öte yandan küreselleşme millî kimlik çatışmaları, millî direncin zayıflatılması gibi bireysel ve toplumsal kültür zafiyetleri üzerinde etki etmektedir (Erkal, 2002, s.227). Bunun daha iyi anlaşılabilmesi için kültür ve millî kültür kavramları üzerinde durmak istiyoruz.

\section{Kültürr ve Davranış}

Ören (1999) “Kültür ve Davranış İlişkisi” adlı makalesinde özetle şunlardan söz etmektedir. Kültürel faaliyet, bir eylem biçimidir. $\mathrm{Bu}$ eylem gerçekleștiği zamanla sınırlı değildir. Nesilden nesile aktarılarak gelen ve her nesilde yeni davranış biçimleri oluşturan ve sonuçlarından etkilenen bir etkileşim zincirinin ürünüdür. Çevre etkenleri açısından davranışla kültürün benzer yönleri vardır. Bir davranışın iki çevresel etkeni vardır. Birincisi davranışın oluştuğu andaki çevresi; ikincisi ise davranışı etkileyen ön yaşantıların oluştuğu geçmişteki çevredir. Davranış iki çevresel etkenin ürünüdür. Kültür de böyle iki çevresel etkenin ürünüdür. Birincisi kültürel olguların oluşturulduğu andaki durum; ikincisi ise kültürü etkileyen kültürel katılımın oluşturduğu geçmişteki kültürel mirastır. Bu benzerlik yanında bu iki olgu arasındaki en büyük fark davranışın bireysel olması kültürün ise bireyler arası ortak bir etkileşimin ürünü olmasıdır.

İnsan; tabiatı ve dünyayı dönüştürdükçe kendisini de dönüştürür. Her bir dönüşüm kendi kültürünü oluşturur. Psikolojinin bilinç ile ilgili çözümlemeleri sosyolojiye, sosyolojinin de toplum ve kültürle ilgili bulguları psikolojiye büyük fayda sağlayacaktır. Benzer ilişski davranış ve kültür arasında da vardır. İnsan davranışının eğitimle geliştirilmesi kültüre, bir çevre faktörü olan kültürdeki gelişmeler de insan davranışlarının gelişimine katkıda bulunacaktır. 
Kültür sadece bir davranış eğilimi değil, aynı zamanda birçok duygu, düşünce ve davranış etkileşimlerinin ürünüdür. Başka bir ifadeyle kültür sadece tek bir bireyin duygu, düşünce ve davranışlarını ürünü değil farklı kültürlerin de etkisi altında oluşan ancak ait olduğu toplumun özellikleriyle anlamını bulan dinamik bir oluşumdur.

Davranış mı kültürü etkilemekte, kültür mü davranışı veya hangisinin sınırları daha geniştir? Gibi sorulara cevap ararken toplumsal ve psikolojik biçimlerin birbirini karşılıklı ve çoğu kez aynı anda etkileyerek insan davranışlarının ortaya çıkardığı varsayımın genel bir kabul gördüğüne işaret edebiliriz.

Kültür, ferdin toplumsal bir varlık olarak kişilik kazanmasında temel bir unsurdur. Davranış psikolojisine göre ise öğrenilmiş bir davranıştır. Kültür insan davranışlarını yönlendiren bir modeli de oluşturur. İnsanın yaptıklarının bir ürünü olan kültür aynı zamanda insanın nasıl hareket edeceğinde de bir model olarak ortaya çıkar. Kültür, ancak insan davranışlarında kendini gösterir. Bütün düşünce akımlarını, yeniliklerini ilerlemelerin hepsi bireyin eseri birey de bir başka ifadeyle kültürün eseridir denilebilir. Bu açıdan bakıldığında kültürü oluşturan asıl unsurların milletlerin gayretleriyle uzun bir tarihî süreç içerisinde oluştuğu gerçeği ile karşı karşıya kalırız. Bu da bizi sosyolojik açıdan ve psiko-sosyal açıdan millî kültür kavramına götürür.

\section{Kültür ve Millî Kültür}

Dilimize İngilizce'den geçmiş kültür kelimesinin kökü Latince "cultura"dan gelmektedir. Cultura, "colere" mastarından türemiştir. Toprağ1 ekip biçmek anlamınadır. Kültür kelimesinin kökü her ne kadar toprağ1 ekip biçme anlamını taşısa da, başka alanlarda da kullanılmaktadır. Bu yaygın kullanım ise kültür kelimesinin anlamına çeşitlilikten ziyade müphemiyet kazandırmaktadır (Meriç, 1993, s.305). 
Batı edebiyatında yüz altmış bir anlamı olan kültür kelimesinin bu mana kargaşasını izale edebilmek için esas olarak üç anlam grubu ile sınırlandırılmıştır. Bunlar:

- Etnoloji ve kültür tarihi mensuplarının kullandığı ve insan mefhumu ile hemen hemen aynı manayı ifade eden ve insanın hayatında içtimai yoldan tevarüs ettiği maddi ve manevi her unsuru kapsayan, anlamıdır. Bir anlamda medeniyet kelimesinin karşılığı denilebilir. Şayet medeniyet kelimesi kullanılmasa idi maddi kültür kelimesi onun yerine geçebilirdi.

- Kültürlü insan tabirinde olduğu gibi, ferdî inceliğin bir ideali anlamındadir.

- Bir milletin dilinin, dininin, tarihinin, sanatının ve örf ve âdetinin bütününden ibarettir.

- Özetle bir formülle ifade edilmesi istenildiği takdirde denilebilir ki kültür, takınılmış bir tavır; medeniyet ise bilme ve yapabilmedir (Turhan, 1987, s.37).

Kültür maddi ve manevi olarak ikiye ayrılmaktadır. Maddi kültür, teknik, araç ve gereçler, makine, üretim araçları ile mekâna bağlı elemanlardır. Bunlar insani ihtiyaçtan sağlayacak bir boyuta ulaştığında medeniyet halini alır.

Manevi kültür ise, bir milleti diğer milletlerden ayırt edebilme imkânı veren örf ve âdetler, ortak davranışlar, değer hükümleri, ahlaki anlayış, sosyal normlar ve zihniyet ile sosyal denetim tezahürleridir (Tural, 1992, s.104).

Ziya Gökalp, kültür kelimesinin Türkçe karşılığını bulmak için lügatleri tararken, aradığı kelimeye karşılık olarak "hars" terimini bulur. (Gökalp, 1972, s.33). Ancak bu kelime bir müddet kullanılsa da yaygınlaşamaz.

Bilahare kültür kelimesinin karşılığı olarak “ekin” kelimesi de kullanıldı ise de, iltifat görmemiştir. 
Güzel Türkçemizde kültür kelimesinin karşılığ1 olarak kullanılması fevkalade isabetli olan bir kelime vardır ki o da "irfan" dır. Batı entelektüelleri irfan kelimesine aslında yabancı değildir. Onların lisanındaki "Gnose” terimi bizdeki "irfan” kelimesinin karşılığıdır. Yani insanın kendini tanıması, keşfetmesi ve de "ilm-i ledün" anlamındaki "gnose" kelimesi bu konudaki meramı anlatmada daha isabetli olsa gerek (Meriç, 1986, s.12).

Cumhuriyet döneminde kültür ve medeniyet terimleri daima tartışma konusu olagelmiştir. Sebebi ise, "Batı medeniyetine girelim fakat kültürümüzü muhafaza edelim” düşüncesidir.

Ziya Gökalp’in, “Türkleşmek, İslâmlaşmak ve Muasırlaşmak” şeklindeki ifadesi veya "Türk milletindenim, İslâm ümmetindenim, Bat1 medeniyetindenim" üçlemesi bu fikrin formüle edilmiş hâlidir (Değirmencioğlu, 1991, s.138).

Ziya Gökalp'a göre medeniyet, bir milletten bir millete geçebilir. Maddidir. Dolayısı ile Batı medeniyetine girmemizde bir mahzur yoktur. Kültür ise dil, din, tarih, sanat, örf ve âdetten oluştuğu için millîdir ve bir milletten başka bir millete geçemez. Binaenaleyh Batı medeniyetine girerken kültürümüzü değiştiremezdik ve değiştirmemeliydik (Gökalp, 2003, s.521).

Bunun yanı sıra kültürle medeniyetin ayrı ayrı tarif edilmesinin sun'î olduğunu gerçekte böyle bir ayrımın olmadığını söyleyenler de vardır. Kültür ve medeniyeti birbirlerinden kesin çizgilerle ayırmanın mümkün olamayacağını söylemekle medeniyetle kültür aynı şeydir, ayrısı gayrısı yoktur demek aynı şey olmasa gerek (Topçu, 1970).

Avrupa'da pek çok milletin bulunduğu sosyal bir vakıadır. Avrupa medeniyetine dâhil olan bu milletler sınırlarını kaldırdılar, para birimlerini ve dolayısı ile iktisadi yapılanmanın müşterek hâle getirdiler. Bütün 
bu birlikteliklerine rağmen kültürlerini oluşturan lisanlarından, tarihlerinden, örf ve âdetlerinden vazgeçerek yekvücut oldular mı?

Buna cevap verebilmek için kimlik-kültür ilişkisine göz atmak gerekir. Siyasi, dini, ailevi, mesleki ve sosyal mensubiyetleri belirten kimlik, aynı zamanda ferdin sosyal rol ve statülerini yansitır. Entelektüel tabakanın genellikle kendilerini millî kültüre nispet etmede sıkıntıları bulunmaktadır. Ancak geleneksel kültürün imanına bağlı kalan hak kesiminin yeni yetişen aydınları, kültürün mukaddeslerine bağlı kalmaya çalışarak kültürel yapıyı yani gerçekleştirilmiş biçimlerini sorgulamaya ve kendi dışına açılmaya başlarlar. Bu kesim yabancı kültürleri tanırken, kendi kimliğini de, aynı mukaddeslere sadık kalarak yeniden kurmaya çalışır (Köseoğlu, 1996, s.88). Buna göre Avrupa Birliği’nde olduğu gibi her ne kadar küresel değerler farklı topluluklarda ve kitlelerde yaygınlaştırmaya çalışılsa da, yerel kültürlerin tamamen yok olacağı düşünülemez. Nitekim ülkemiz bağlamında Batı'ya hayranlık duyan aydınlarımızın birçoğunun, belli bir bilgi birikimine ulaştıktan sonra Batıyı sorgulamaya başladıkları görülmektedir. Bu Batı ile tanışma ve araştırma sonucu oluşan bilgi birikimi sonucu ortaya çıkan sorgulama, kendi kültür ve mukaddeslerini yeniden gözden geçirmeye götürür.

Kültür ve medeniyet arasındaki temel fark, medeniyet ferdî bilgilere, tecessüse, ilim ve tekniğe dayanan, konforu ve yaşama imkânlarını arttırmayı hedef alan, millî rengi olmayan faaliyet ve eserlerdir. Kültür duygulardan, medeniyet bilgilerden mürekkeptir. Medeniyetin milliyeti yoktur. Aklın ve ilmin doğurduğu bir birikimdir. Hatta tekniktir. $\mathrm{Bu}$ nedenle teknoloji bir medeniyet ürünüdür.

Küreselleşmenin temel boyutu kültürdür. Kültür kavramı küreselleşmekte olan ve kültürel tasavvurların yayılmasında kullanılan iletişim ve medya teknolojileri bağlamında ele alınmaktadır. İletişim teknolojilerinin küreselleşme süreci içinde kesinlikle merkezî bir konumu olmasına 
rağmen, bu teknolojilerin gelinim süreçleri kültürel küreselleşme ile özdeş değildir. Aslına bakılırsa iletişim teknolojilerinin etkileri hem daha geniş hem de daha sınırlıdır. Geniştir çünkü bu teknolojilerin küreselleşmenin ilerlediği bütün boyutlarda önemli bir rolü vardır. Aynı zamanda sınırlıdır; çünkü iletişim araçları sembolik anlam inşası sürecinin ancak bir kısmını oluşturur ve küreselleşmenin kültürel olarak tecrübe edildiği alanlardan ancak biridir (Tomlinson, 2004, s.37).

Bununla birlikte medeniyet ile kültür arasında doğrudan bir etkileşim söz konusudur. Özellikle maddi kültürün medeniyetle yakın bir ilişkisi vardır. Kültür yarattığ 1 insan unsuru ile medeniyetin gelişmesine ve ilerlemesine tesir ettiği gibi, medeniyet de kültür değerlerinin şekillenmesinde ve değişmesinde rol oynayabilir (Tural, 1992, s.85).

Bu nedenle yukarıdaki soruyla ilgili olarak hepsi Batı medeniyeti dairesinde bulunmasına rağmen, bir İngiliz’i Alman'dan, bir Fransız’1 İspanyol'dan, bir İtalyan'ı İskoçyalı'dan ayıran kendilerine has kültür değerleri vardır. Bütün bu milletlerin verdiği değerlerden Batı medeniyeti doğmuştur.

\section{Küreselleşmenin Dayandığı Temeller}

Küreselleşmenin, ülke sınırlarını aşarak dünyayı bir köy hâline getireceği tezi, teknoloji ve öncellikle iletişim teknolojisinin kapsama alanının bütün dünyaya ulaşmasıyla bir anlamda gerçekleşme yolundadır.

Küreselleşmenin dünyayı küçük bir köy yapıp yapamayacağını anlayabilmek için küreselleşmenin dayandığı temellerin bilinmesinin zaruri olduğunu düşünmekteyiz. Zira bu temeller bir yanı ile medeniyetin eseri iken, öbür tarafı ile kültürlerin etkisini de taşımaktadır.

Küreselleşmenin üç temel ayağının olduğu ve üç temel dayanağının yanı sıra bir de uygulayıcılarının bulunduğu söylenebilir.

Küreselleşmenin üç temel ayağını; bilim, teknoloji ve iktisadi güç 
veya sermaye olarak ifade etmek mümkündür.

Bu üç temel dayanağın üçüncüsünün yan kolu olarak küreselleşmenin uygulayıcıları konumunda olan, uluslararası gibi gözüken ve fakat uluslararası olmayıp Batı'nın kontrolünde bulunan kurumlar vardır. Bunlar UNESCO, UNICEF, NATO, BM ve AB olup, bu kurum ve kuruluşlardan da bahsetmek konunun vuzuha kavuşması için zaruri olsa gerektir.

Küreselleşmenin dayandığı bu üç temel dayanağın önemi gücünü bunlardan almasından kaynaklanmaktadır. Bunlar nitelikleri itibari ile her zaman daima gücün kaynağı olan dayanaklardır.

\section{Bilim}

Küreselleşme aslında sadece maddi refah olarak algılanmamalıdır. Küreselleşme aynı zamanda bilim ve teknolojinin hâkimiyeti olarak da görülmelidir. Küreselleşmenin sadece iletişim, ulaşım, sağlık vs. alanlarındaki gelişmeler olmadığını, bunun bütün bir bilimsel gelişmeye bağl1 bulunduğunu gözden 1rak tutmamak gerekiyor.

İnsan bilinçli bir varlıktır. Etrafındaki nesneleri ve aynı zamanda bir nesne olarak kendisini de algilar, anlar ve anlamlandırır. Yani hem özne ve hem de nesne durumundadır.

Algılayan, anlayan ve anlamlandıran olması münasebeti ile insan özne ve algılanan varlıklar nesne olarak bir ilişki içine girmiş yani bir akit oluşturmuş olurlar. İşte burada anlatılmaya çalışılan özne ve nesne ilişkisine bilim denilmektedir. Bilimin çeşitleri veya bir başka ifade ile sınıflandırılmaları vardır. Ancak bunlar şimdilik bizim konumuzun dışında kalan hususlardır. Bizi ilgilendiren bilimin orijini (menşei)dir. Bilimin kaynağı hakkındaki fikir, düşünce veya inanç bilimin etkisini, sınırlarını ve önemini belirleyecektir (Copleston, 1988, s.89).

Günümüz medeniyetinin oluşumunda en önemli amil olan bilim, belli dönem ve alanlarda pozitivist olmuştur. Bilimin bu pozitivist yönü 
nesnel, nedensel ve genel ölçülebilirlik ilkeleri ile bilimsel terakkiye en önemli katkıda bulunmuştur denilebilir.

Küreselleşmenin dayandığg ve günümüz medeniyetinin temelini oluşturan bilimin (nesnel, nedensel ve genel ölçülebilirlik) nitelikleri ve bunun oluşturduğu teknolojinin nasıl bir gelecek, kültür ve medeniyet oluşturacağı veya inanları ne hâle getireceği hakkında iki fütürolog George Orwelll ve Aldous Huxley’in görüşlerine bakmanın faydalı olacağı kanaatindeyiz.

1984 adlı eserinde George Orwell, kitapları yasaklayacak olanlardan korkuyordu (Orwell, 1958). Aldous Huxley'in görüşü ise kehanetten farklıyd1. Brave New World (Cesur Yeni Dünya) adlı eserinde Huxley, insanların süreç içinde üzerlerindeki baskıdan hoşlanmaya, düşünme yetilerini körelten teknolojileri yüceltmeye başlayacaklarından söz ediyordu.

Huxley'in korkusu ise kitapları yasaklamaya gerek duyulmayacağ1, çünkü kitap okumak isteyecek kimsenin kalmayacağ1 şeklindeydi. Orwell, bizi enformasyonsuz birakacak olanlardan, Huxley pasifliğe ve egoizme sürükleyecek kadar enformasyon yağmuruna tutacak olanlardan korkuyordu. Orwell, hakikatin bizden gizlenmesinden, Huxley, hakikatin umursamazlık denizinde boğulmasından korkuyordu. Orwell, tutsak bir kültür hâline gelmemizden, Huxley, duygu sömürüsüne dayanan içki âlemleri ve tek başına iple asılı bir tenis topu ile oyalanmak gibi şeylerle ömür tüketen önemsiz bir kültür yapısı oluşturup onu yaşamamızdan korkuyordu. Huxley'in, Brave New World'da belirttiği gibi, tiranlığa karşı direnmek üzere daima tetikte bekleyen kamusal özgürlükçüler ile rasyonalistler "İnsanın neredeyse sonsuz olan eğlenme açlığını” hesaba katmamışlardı. Orwell'in 1984'ünde insanların acı çekerek denetlendiğine dikkat çekerken; Huxley Brave New World'da insanlar hazza boğularak denetlenmektedir. K1sacası Orwell bizi nefret ettiğimiz şeylerin mahvetmesinden korkarken; Huxley bizi sevdiğimiz şeylerin mahvedeceğinden 
korkuyordu (Huxley, 1965, s.118).

Özetle Orwell bizi nefret ettiğimiz şeylerin mahvetmesinden korkarken, Huxley sevdiğimiz şeylerin mahvedeceğinden korkuyordu. Onlardan birisi insanların hürriyetleri üzerine uygulanan istibdattan korkarken, diğeri, insanın nefsinin esiri hâline getirileceği bir sistemi daha gerçekçi bir tehlike olarak görmekteydi. Dünya bir küresel köye dönüşecekti ama küresel köyün kavalcısı da insanları uyutmak ve uyuşturmak için iş başında bulunacaktı. Küresel köyün kavalcısının elindeki kaval da medya ve özellikle televizyon olacaktı (Postman, 1994, s.7).

Günümüz medeniyetinin ve bugünkü küreselleşmenin etkisinin tıptan psikolojiye, siyasetten sosyolojiye, iktisattan reklam furyalarına kadar her alanda etkisini görmek mümkündür. Psikolojik açıdan küreselleşmenin temelini oluşturan gerek Pavlovizm'in ve gerekse Watsonizm'in insanı sadece etki ve tepkinin gözlemlenmesinden ibaret nesnel bir varlık olarak görmesi sonucunda da insanlığından, dolayısı ile kitaptan, kütüphaneden uzaklaştırdığı dikkate alındığında Huxley ve Orwell’e hak vermemek imkânsız görünmektedir.

\section{Teknoloji}

İnsanların davranışlarını izah ederken, çok defa onların davranışları ile o kimselerin fikirleri arasında bağ kurarız. Fikirlerle davranışlar arasında bir sebep-netice münasebetinin varlığını kabul ederiz. O hâlde küreselleşme, teknoloji, onu icat edenler, teknolojinin temeli olan bilimin anlaşılması ve izahı konusunda bunları ortaya koyan insanların fikirlerinin işin temelinde niçin önemli bir rolü olmasın?

Küreselleşme olarak ifade edilen bahis mevzusu değişimde, bilginin pratik maksatlarla organize edilmesi yani, teknoloji en cazip ve en göze çarpıcı olarak yer almaktadır.

Bütün teknolojik gelişmenin arkasında bilimsel bilginin bulundu- 
ğunu kabul etsek bile, bilimsel bilginin büyük insan kitleleri için çok çekici ve çabuk elde edilebilen bir şey olmadığı muhakkaktır.

En basit şekli ile bilimin pratiğe aktarılması olarak tarif edilen günümüz teknolojisini, McDermott "somut ve deneye dayalı anlamında, esas itibari ile organizasyonel hiyerarşi yolu ile çalışan ve teknik maharet sahibi bulunan küçük grupların büyük insan grupları, olaylar ve makineler üzerinde kurdukları akılcı kontrol sistemleri” şeklinde tanımlamaktadır (McDermott, 1981, s.142).

Teknik maharet sahibi diye nitelediğimiz, teknolojiyi icat eden söz konusu az insan grubunun ne tür bir kültür içinde doğup büyüdükleri, yaşadıkları kültürel yapı, hayat felsefesi, hayat telakkileri iyi bilinecek olursa dünyayı bir köy gibi yapacaklarını, yapmak istediklerini yani küreselleşmeyi ve hedeflerini daha iyi anlayabiliriz.

Küreselleşme ve öncüleri arasındaki fikrî irtibata açıklık getirmek üzere Denis Goulet'in çağdaş Batı teknolojisinin özelliklerine ait fikirlerini burada serdetmekte fayda mülahaza etmekteyiz. Bu teknolojinin oluşum kaynağı olan çağdaş Batı düşüncesinin niteliklerini şöyle özetlemiştir;

1. Özel bir rasyonalite (akılcılık) anlayışı, (yapılan işin en doğrusunun yapılması ve fakat en doğru olanın yapılmasının tefriki konusunda acze düşülmesi),

2. Küreselleşmenin belki de en büyük amacı olan tabiatla uyum yerine ona hâkim olma ve kullanma temayülü,

3. Akılcılığın temelinde insan yaşantısını tahlil edebilen parçalara ayırma ve bunları tek tek ölçüp tesirlerini arama,

4. Üretkenlik ve verimlilik anlayışının hayata hâkim olması ile her şeyin kâr artırıcı açıdan ele alınması ve insanî değerlerin üretim hesaplarının dışında tutulması (Güngör, 1995, s.37). 
Rasyonalitenin temelinde insan yaşantısını tahlil edebilen parçalara ayırma, Orwell ve Huxley'in fikirlerinde olduğu gibi ve bunları tek tek ölçüp tesirlerini arama tavrı vardır. Yani günümüzdeki küreselleşmeyi yaygınlaştıranlar insan tabiatını istediği gibi yeniden inşa edebileceği fikrine varmış ve bu fikrin bütün mantıki sonuçlarını ortaya çıkarma yolunda seferber olmuştur. Üretkenlik ve verimlilik anlayışlarının insanlığın hayatına hâkim olması bu sonuçlardan sayılmalıdır.

\section{İktisadi Güç veya Sermaye}

Asrımız ve özellikle son onlu yıllar son derece önemli teknolojik gelişmelere şahitlik etmektedir. Sanayi devriminin oluştuğu 18. yüzyı1daki su ve buhar gücünün yaygın olarak kullanılması, demir yollarının yapılması, demir çelik ve tekstildeki gelişmeler en etkili olanlarının başında gelmektedir denilebilir. İçten yanmalı motor ve elektrik gücünün devreye girmesi bugünkü teknolojinin ayak sesleri mesabesindedir.

Bilhassa günümüze damgasını vuran elektronik buluşlar sonucunda dijital ağlar ve yeni temel teknolojilerin ürün ve üretim süreçlerinde esaslı bir role sahip olması, iktisatta küreselleşmenin hızını ve gücünü artıran inkârı imkânsız bir gerçekliktir.

Özellikle mikro elektronik ve bilgi teknolojileri başta olmak üzere nanoteknoloji ve mikro nanoteknoloji olarak adlandırılan yeni teknolojiler yalnızca tüketime sunulan elektronik ürünlerde bir dizi önemli gelişmeye yol açmadı; bunun yanı sıra yeni araç ve ekipmanların imal edilmesine ve ileri imalat ekipmanlarının üretilmesine de sebep olmuştur. İleri imalat ekipmanları imalat süreci üzerinde rekabet gücünü önemli ölçüde etkileyen birçok yeni niteliğin ortaya çıkmasını sağlamıştır. Üretilen ürün ve üretim ekipmanlarının hacimce küçük olması, üretim süreci ve ürünlere güvenilirliğin artması, uyumlu olma, modüler olma, işlem hızı ve düşük enerji tüketimi bu tarz özelliklerdendir. 
Yeni teknolojiler bilgi ve iletişim akımlarını iyileştirmeyi ve firma içindeki işçi ve yöneticilerin karar alma ve koordinasyon ve iş birliği kapasitesini amaçlayan örgütsel değişiklik ve yeniliklere de yol açmıştır.

Yeni teknolojiler üretim sürecinin esnekliğini artırdığından; başka bir ifade ile yeni teknolojiler daha az zamanda piyasaya daha fazla yeni ürün sürülmesine ve tüketici tercih ve taleplerine uygun olarak mevcut ürünlerin kalitesini artırmaya imkân tanıdığg için rekabet gücünün artırılması yalnızca maliyetleri azaltmaya değil bunun yanı sıra sürekli yenilik ve icatta bulunma, tüketici talep ve tercihlerine hızlı bir şekilde cevap vermeye bağlı bir hâle gelmiştir (Kutlu, 1998, s.384).

İnsanların ihtiyaçlarını tespit ederek üretimi ona göre yapıp insanlara ve insanlığa hizmet etmek anlayışı yerine, para kazanmak veya daha genel bir ifade ile kâr amaçlı olarak inananlarda ihtiyaç oluşturup onların elindekilerini almaya yönelik tutum ve davranışları sadece iktisat teorileri ile açıklamak mümkün olmasa gerek. Nitekim ABD'deki adı ile davranışçı1ık, Rusya'daki ismi ile klasik koşullanmanın prensiplerinden hareket ederek, insanları şartlandırarak, iradelerine ipotek koyarak satışı artırma bunun için bir örnek teşkil edebilir.

Küreselleşen dünyada iktisadi açıdan bir ülkenin sınırları içerisinde kalmak veya bir şirketin sermayesi ile yetinmek artık imkânsız hâle gelmiştir. Zira üreten, ürettiklerini tüketemez veya üretilen malların eskimesi beklendiğinde yeni ürünlerin üretiminde ve arzında çok ciddi kısıtlamaların yapılması kaçınılmaz olacaktır.

Ticaret, sanayi/teknoloji ve bankacılık sermayesi ABD'den Avrupa'ya veya Japonya'ya doğru karşılıklı olarak yer değiştirerek küresel sermayeyi oluşturmada başı çekmektedirler.

Ülkelerin kendilerine yetecek bir düzeni muhafaza etmeleri artık söz konusu değildir. Korumacılık terk edilerek dışa açılma adı altında 
ülkeler iktisadi yapılarının dünya ile bütünleşme çabasını benimsiyorlar (Rodrik, 1997, s.36).

Küreselleşme sürecinde, küresel sermaye millî sınırların önemini ortadan kaldıracak ve millet-devletin iktisadiyat üzerindeki denetimini etkisizleştirecek güce sahip olduğunu zaman zaman yaptığ 1 operasyonlarla göstermektedir. Daha açık söylemek gerekirse dünya üretimi ve iş bölümü az sayıda büyük ve uluslar üstü şirketlerin denetimi altındadır. $\mathrm{Bu}$ şirketler üretim bilgisini/teknolojisini ellerinde tuttukları gibi devletlerin ekonomi politikalarını ve yatırım kararlarını büyük ölçüde belirliyorlar (Hirst, Thomson, 2003, s.67).

Önemle belirtelim ki, globalleşme sürecinin hızlanmasında global ticaret ve finansta ortaya çıkan yeni araçlar ve ilerlemeler de oldukça etkili olmuştur. 1929 yılında Lüksemburg'da ilk off-shore finans kurumunun oluşturulması, II. Dünya Savaşı sonrasında 1944 yılında Dünya Bankası'nın kurulması, 1954 yılında İrlanda'da ilk serbest bölgenin oluşturulması, 1971 yılında Nasdaq'ın faaliyete başlaması, bir sonraki yıl finansal türev piyasalarının devreye girmesi, 1977 yılında SWIFT olarak bilinen bankalar arası elektronik fon transferinin başlatılması, 1995 yılında GATT’’n yerini Dünya Ticaret Örgütü'nün alması gibi olaylar globalleşme sürecini hızlandıran başlıca olaylardır. Global finans piyasalarındaki bu gelişmeler finans piyasalarında bazı krizleri de gündeme getirmiştir. 1987 yılında Wall Street Borsa’sında yaşanan çöküş ve 1997 yılında Asya-Pasifik ülkelerinde yaşanan global ekonomik kriz finansal globalleşmenin negatif etkileri olarak değerlendirilmiştir" (Kloby, 2005, s.270).

Dünya ekonomisine daha etkin yön verebilmek için küresel sermaye, uluslararası gibi gözüken fakat kendi kontrolünde bulunan birtakım iktisadi bütünleşme veya bölgeselleşme hareketlerini hızlandırmıştır. Serbest ticaret bölgeleri, gümrük birlikleri, ortak pazarlar, ekonomik 
birlikler, tercihli ticaret anlaşmaları bu konuda örnek olarak söylenebilecek organizasyonlardır (Hirst, Thomson, 2003, s.33).

Güneydoğu Asya ülkelerinin oluşturduğu ASEAN, Asya Pasifik İş Birliği APEC veya uluslararası Para Fonu IMF örnek olarak zikredilebilecek küresel ekonomik iş birlikleridir. Bunların yanı sıra diğer birtakım iş birliği hareketleri de vardır. Ekonomik İş Birliği Teşkilatı ECO, Karadeniz İş Birliği KEI ve İslâm Konferansı Teşkilatı İKT gibi. Ancak bu ekonomik iş birliği hareketlerini ortağı olan devletler en azından gelişmekte olan devletler oldukları için, hem bilimsel bilgi ve hem de teknolojik açıdan yeterli olmadıklarından olsa gerek, geçen bunca zamana rağmen gerekli mesafe alınamamış ve etkin olunamamıştır.

Hiçbir iktisadi teori veya faaliyet insan unsuru dikkate alınmadan tam izah edilemez. Gerçekte iktisadi faaliyetlerin dış karakteristikleri altında derinliğine bakılınca bir duyuş ve inanış dünyasının saklı olduğu anlaşı1ır. Konuya hangi tarafından bakı1ırsa bakılsın, iç ve dış âlemin alt alta tabakalanışı açıkça görülür. "Dizi dizi rakamlar, formüller, göz doldurucu gösteri ve göstergeler! Ancak bütün bu dizileri ve matematik bağlantıları temelde insanı hiç yokmuş gibi düşününce işin rengi değişiyor. Ekonomik düzenin son kertede insan davranışımızla belirlenmiş olacağını kolaylıkla gözden kaçırıyoruz. Aynı usuller, aynı teknoloji bir yerde istenileni verirken bir başka yerde tam aksi sonuçlara ulaşıyorsa, farkın usul ve aletlerden çok onları kullananın vasıflarından gelmiş olabileceği bugün bile yeterince anlaşı1mıştır denemez. Sombart'1n 1920'lerde "Modern Kapitalizm"i kaleme alırken en fazla yakındığı nokta da bu idi: Aradan canlıyı çıkararak ekonomiyi cansız madde yığınları olarak görmek!" (Ülgener, 1981, s.11).

Küreselleşmenin önemli bir boyutu olan sermaye, kapitalist bir zihniyetle hareket etmektedir. Bu da globalleşmenin etkin olduğu insan gruplarındaki düşünce yapısını şekillendirmektedir. 
$\mathrm{Bu}$ bağlamda küreselleşmeye kaynaklık eden güçlü ülkeler etkinliklerini her alanda gelişmekte olan ülkeler üzerinde sürdürmektedir. $\mathrm{Bu}$ nedenle Batı düşüncesinin katkıda bulunduğu küreselleşme, aynı zamanda Batı kültürünü de beraberinde ihraç etmektedir.

Küreselleşme denilen süreç yol aldıkça, gelişmekte olan ülkelerin kalkınması da zorlaşmaktadır. Zira üretimin küreselleşmesi bölgesel bütünleşme ve çok taraflı ticaret anlaşmalarının dayattığı kurallar, kalkınmayı güçleştirmektedir. Bu bakımdan, Türkiye millî kültürün ve millî kurumların gözetiminde kendi kalkınma stratejisi planlayıp uygulamaya koyacak ve gecikmiş kalkınmasını gerçekleştirecek tedbirleri almak durumundadır (Gürses, 1998, s.65).

Bir toplumu yönlendiren politikalar yalnızca ekonomi politikaları değildir. Aksine ekonomik yapının temelinde ona uygun toplumsal yapılar oluşmuştur. Bu toplumsal yapılaşmanın daha dinamik bir toplum ve daha verimli bir ekonomik süreç oluşturabilmesi için sosyal politikalara ihtiyaç vardır. Bu sebeple rekabetçi bir toplumda rekabet sürecinin tabanı olarak orta tabakayı güçlendirici, refahı tabana yayıcı, eğitim ve öğretimde yapıcı ve yaratıcı şahıslar yetiştirmeye yönelik sosyal ve kültürel politikalara ihtiyaç vardır.

\section{Sonuç ve Teklifler}

Kültür statik değil dinamiktir. Hatta bir milletin her dönemi için bile aynı kültür tanımı yapılamaz. Çünkü sürekli gelişmektedir. Yine kültürel kimlik, eğitim ve sosyalleşme yoluyla ferde kazandırılır; onun kişiliğine, düşünce, tavır ve davranışlarına yansır. Bu nedenle millî karakter dediğimiz insani özellikler o kültüre mensup kişilerde tezahür eder. Baskın kültüre direnmek kültür milliyetçiliği ile mümkün değildir. Üreten kültür, diğer kültürleri etkiler ve yönlendirir. Öte yandan kültürün 
değişmesi her zaman olumsuz değildir. Toplumda kültürün değişmesi, o toplumun dinamizminin de bir yansımasıdır. Burada asıl olan kültürü korumak çabası yerine kültürü dinamik hâle getirip üretken kılmaktır.

Küreselleşme; gücünü sahip olduğu bilim, teknoloji ve bunların sonucu elde edilen sermayeden (para) almaktadır. Bilim, teknoloji ve sermaye her dönemde kendi çapında varlığını sürdürmüş ve kimin elinde ise onu iktidar sahibi yapmıştır.

İnsanoğlu bilimin gücünü kavramış ve insanı yücelttiği için onu baş tacı yapmıştır. Bilime karşı durmak ile bilimi kendi menfaati veya egosunu tatmin için varlıkların aleyhine kullanan hayat telakkisine karşı çıkmak aynı şeyler olmasa gerek. Bilimi elinde bulunduran ve onu ihtirasları uğruna yanlış şekilde kullanan zihniyete karşı çıkılabilir ama bilime ve bilimin pratik hayata uygulanışı demek olan ve hayatımızı kolaylaştıran teknolojiye karşı durmak veya onu reddetmek mümkün gözükmemektedir. Bugüne kadar da teknolojiye karşı çıkarak basan kazanmış ne bir millet ne de bir lideri henüz tarih kaydetmemiştir. Ancak teknoloji insan eseri olduğuna göre onu yapan kadar kullananın da kullanma tarzı ile ilgili iradesi, tavrı ve düşüncesi etkin olabilir ve hatta olmalıdır da. Yani teknolojinin olumsuz tesirlerini asgariye indirebilmek için ona teslim olmak yerine mücadele etmek elbette ki olması gereken bir durum olsa gerek.

Bilimin pratik hayata uygulanması şeklinde basitçe tarifi yap1lan teknolojinin doğurduğu küreselleşmenin olumsuzluklarını bertaraf etmek veya asgariye indirmek için yapılması gerekenleri özetle şöyle ifade edebiliriz:

1. Küreselleşme önemli bir yönü ile sosyal bir olaydır. Sosyal olaylar ise çok yönlüdür ve sosyal olaylar da fiziki olaylar gibi, boşluk kabul etmez. Dolayısı ile ilk yapılması gereken küreselleşmenin kültürel, sosyolojik, psikolojik, siyasal ve iktisadi vs. her yönü ile ele alınarak çok 
ciddi bir şekilde tahlil edilip iyice anlaşılmalı ve ilgili herkese anlatmalı ve anlaşılması sağlanmalıdır. Zira bilinmeyen veya bilinemeyen her olay veya olgu veyahut "şey" hem başarısızlığı ve hem de korkuyu doğuran en önemli sebeptir.

2. Milli kültürü oluşturan bilhassa dil, din, tarih, sanat ve örf ve âdetlerimizi her ferdin çok iyi bilmesi için örgün ve yaygın eğitime düşen sorumluluklar ve vazifeler belirlenmeli ve tavizsiz bir şekilde uygulanmasını temin etmeliyiz.

3. Milli kültürün bir hayat tarzı olarak benimsenebilmesi için yaygın eğitim kurumlarından sayabileceğimiz en şümullü ifadesi ile medya da üzerine düşeni yapması konusunda yönlendirilmeli ve bilinçlendirmelidir.

4. Yetişmekte olan nesillerimizi elbette ki dünyadaki değişimden haberdar etmeliyiz. Evrensel değerleri bilmeliler. Ancak aynı derecede, hatta daha iyi bir şekilde kendi millî değerlerimizi ve erdemlerimizi de öğretmeliyiz. Aynı zamanda evrensellik ile küreselliğin de farklı olduğu bilincine varmalıdırlar.

5. Evrensel değerlerden bahsederken millî erdemlerimizin evrensel değerlerden hiç de geri olmadığı bilhassa insanlık adına bugün var olan faziletlerin tarihimizde en güzeli ile bizde var olduğu anlatılmalıdır.

6. Batı'nın bilim ve teknolojik üstünlüğü karşısında asla eziklik ve eksiklik duymadan, aşağılık duygusuna kapılmadan başarıya ulaşmak için millî kültürümüzü çok iyi bilmenin ve kendimize güvenmenin ol-mazsa olmaz bir husus olduğu gençlere çok iyi anlatılmalıdir.

7. Kültürler ve medeniyetler arası geçişler veya alışverişlerin olması yani, serbest kültür değişmesinin vuku bulması kaçınılmazdır. Ancak iletişim hâlinde olduğumuz kültürlerden bir şeyler alırken körü körü-ne taklit ederek alınmamalı ve aldıklarımız millî bünyeye uygun hâle 
getirilmelidir. Kaldı ki taklit hiçbir zaman ne kadar iyi taklit edilmiş olursa olsun aslı kadar hem iyi hem de kıymetli de olamaz. Taklitçilik yaratıcılığı öldüren en önemli amillerdendir. 


\section{Kaynakça}

Aktan, C. ve C, Şen, H. (1999). Globalleşme, ekonomik kriz ve Türkiye. Türkiye Küçük ve Orta Ölçekli İsletmeler Serbest Meslek Mensuplarl ve Yöneticileri Vakfi Ekonomik, Sosyal ve Siyasal Araştırmalar Serisi. 7 (11), Ankara.

Boratav, K. (2004). Emperyalizm mi küreselleşme mi? A. Tonak (Ed.) Küreselleşme içinde (21-31). İstanbul: İmge Yayınları.

Bostanc1, M. N. (1990). Kültür ve değişme. İstanbul.

Bussolo, M. ve Round, J. I. (2006), "Poverty and policy in a globalising economy", Globalisation and Poverty, New York: Routledge.

Copleston, F. (1988). Felsefe tarihi: çă̆daş felsefe Ingiliz filozoftan. (A. Yardımlı, Çev.). İstanbul: İdea Yayınları.

Değirmencioğlu, M. (1991). Sosyoloji konuşmaları, Ankara: Ecem Yayınları.

Erkal, M. (2002). Küreselleşme, değişme ve dini hayat. Çă̆ımızda Sosyal Değişme ve İslam içinde (227). İstanbul: T.D.V.

Gökalp, Z. (1972). Hars ve medeniyet, Ankara: Diyarbakır'ı Tanıtma ve Turizm Derneği Yayınları.

Gökalp, Z. (2003). İnkılâpçılık ve muhafazakârlık, A. Çiğdem (Ed.), Modern Türkiye'de Siyasî Düşünce - Muhafazakârlık içinde 5 (521). İstanbul: İletişim Yayınları.

Güngör, E. (1980). Kültür değişmesi ve milliyetçilik. Ankara.

Güngör, E. (1995). Dünden bugünden, tarih-kültür-milliyetçilik, İstanbul: Ötüken Neşriyat

Gürses, M. (1998). Küresel ekonomi: Şirket yapısındaki değişiklikler, dış ticarette şirketlerin yönlendirici işlevleri ve küreselleşme sonrasında gelir dağılımı üzerine. Maliye Yazlarl Dergisi. 128, 63-66.

Hirst, P. ve Thomson, G. (2003). Küreselleşme sorgulanıyor. Ankara: Dost Kitabevi.

Huxley, A. (1965). Brave new world. ABD: Harper Perennial.

Kızılçelik, S. (2004). Zalimler ve mazlumlar; Küreselleşmenin insani olmayan doğası. Ankara: Anı Yayınları.

Kloby, J. (2005). Küreselleşmenin sefaleti. (O. Düz, Çev.). İstanbul: Güncel Yayınları. 
Köseoğlu, N. (1996). Türk kimliği ve Türk dünyass. İstanbul: Ötüken Yayınları.

Kutlu, E. (1998). Küreselleşme ve etkileri. Anadolu Üniversitesi İ.I.B.F Dergisi, XIV, (1-2) 384, Eskişehir.

Marshall, M. ve Powers, B. R. (1992). The global village. Oxford University Press.

McDermott, J. (1981). Technology: The opiate of the intellectuals, A. H. Teich (Ed.), Technology and man's future (142). New York: St. Martin's Press.

Meriç, C. (1986). Kültürden irfana, İstanbul: İnsan Yayınları.

Meriç, C. (1993). Sosyoloji notlarl ve konferanslar, Ü. Meriç (Der.), İstanbul: İletişim Yayınlar1.

Meriç, Ü. (2002). Küreselleşme ve dünya dinleri. Çă̆ımızda Sosyal Değişme ve İslam (18). İstanbul: T.D.V.

Orwell, G. (1958). 1984. (V. Turhan ve S. Tonguç, Çev.), İstanbul: Işık Kitabevi.

Özakpınar, Y. (2007). İslam dünyasında kültür değişmesi. Çă̆ımızda Sosyal Değişme ve İslam (550). Ankara: T.D.V.

Petras, J. (2002). Küreselleşme ve direniş. (A. Ekber, Çev.), İstanbul: Cosmopolitik Kitaplığ 1 .

Postman, N. (1994). Televizyon: öldüren eğlence. (O. Akmhay, Çev.), İstanbul: Ayrıntı Yayınlar1.

Rodrik, D. (1997). Sense and nonsense in the globalization debate. Foreign Policy.

Tomlinson, J. (2004). Küreselleşme ve kültür. (A. Eker, Çev.), İstanbul: Ayrıntı Yayınları.

Topçu, N. (1970). Kültür ve medeniyet. İstanbul: Hareket Yayınları.

Tural, S. (1992). Kültürel kimlik üzerine düşünceler. Ankara: Ecdad Yayınları

Turhan, M. (1987). Kültür değişmeleri: sosyal psikolojik bakımdan bir tetkik, İstanbul: MÜIF Vakfi Yayınları.

Ülgener, S. E. (1981). İktisadi çözülmenin ahlak ve zihniyet dünyası. İstanbul: Der Yayınları.

Wood, E. M. (1999). Küreselleşme mi? Emperyalizm mi? Piyasacı efsanenin çöküşü. (F. Başkaya, Çev.), Ankara: Ütopya.

Wright, R. (2000). Will globalization make you happy. Foreign Policy. 